\title{
Analisis Kekasaran dan Kepresisian Hasil Surface Grinding pada Mesin Okamoto Grind-X ACC84ST Dengan Material DIN CK-45
}

\author{
Andhy Rinanto, Hoedi Prasetyo, Agus Kurniawan, Baruna Arya Putra W, Bobby \\ Muhammad R, Cahyanto Onky S, Nikolaus Alun Prapanca H \\ Program Studi Teknik Mesin Industri, Politeknik ATMI Surakarta, \\ Jl. Mojo no 1, Karangasem , Laweyan, Surakarta 57145 \\ *Penulis korespondensi: andhy.rinanto@atmi.ac.id
}

Histori artikel: diserahkan 15 September 2020, direviu 17 September 2020, direvisi 26 September 2020

\begin{abstract}
Surface grinding is the finishing process that needs high smoothness and precision. This process's main demands are precise, roughness, and not burnt. This analysis purposed to know the most influential variable for the roughness and precision of a product. This analysis is also carried out to determine roughness and accuracy that can be achieved using the Okamoto Grind-X ACC84ST machine. The variables used for this analysis are the depth of cut, feeding, and cycle per feed. Every variable has three levels. DIN CK-45 material is selected to be specimen because it is usually used by the manufacturing and automotive industries to make the main product. The Taguchi method is used to reduce the time and number of experiments conducted to obtain more accurate data. The most influential variable for roughness is cycle per feed, while the most significant variable for precision is the depth of cut. The roughness that can be achieved using the Okamoto Grind-X ACC84ST machine is in the range of 0,075 $\mu \mathrm{m}$ (N3) to 0,175 $\mu \mathrm{m}$ (N4). Size deviations that occurred in this study ranged from $-0,007 \mathrm{~mm}$ to $0,005 \mathrm{~mm}$.
\end{abstract}

Keywords: Roughness, Precise, and Surface grinding

DOI: https://doi.org/10.18196/jqt.020117

Web: https://journal.umy.ac.id/index.php/qt/article/view/9982

\section{PENDAHULUAN}

Penggerindaan berasal dari kata gerinda yang menurut Kamus Besar Bahasa Indonesia adalah batu asahan yang berputar. Menurut Kumar dan Dhanabalan (2018), proses penggerindaan adalah pemindahan material dan proses finishing permukaan di mana material dikeluarkan dari permukaan kerja dalam fase chip kecil dengan proses partikel abrasif kecil roda gerinda. Sedangkan menurut Banga dan Sharma (2009), proses penggerindaan dibagi menjadi 4 macam, yaitu cylindrical grinding, internal grinding, center less grinding, dan surface grinding.

Surface grinding adalah proses penggerindaan untuk mendapatkan permukaan yang rata, bersudut, dan berkontur dengan meletakkan benda kerja di atas meja magnet lalu batu gerinda menyayat permukaan benda kerja untuk mendapatkan kehalusan lebih. Hasil proses penggerindaan dapat mencapai kekasaran N3 dengan nilai Ra 0,1 $\mu \mathrm{m}$. Selain kekasaran, kualitas yang dituntut dari proses penggerindaan permukaan adalah kepresisian ukuran (Banga \& Sharma, 2009).

Kumar \& Bhatia (2015) menyatakan bahwa dalam proses penggerindaan, parameter yang paling menentukan kekasaran suatu produk adalah kecepatan putar roda gerinda, kecepatan benda, feedrate, dan depth of cut. Penelitian tersebut dilakukan dengan menggunakan empat parameter dan tiga level pada setiap parameternya. Hasil penelitian menunjukkan bahwa parameter terbaik untuk mengerjakan produk dengan material En15AM berada pada kecepatan roda gerinda sebesar 2000 RPM, feedrate $275 \mathrm{~mm} / \mathrm{menit}$, dan depth of cut 0,06 $\mathrm{mm}$.

Penggerindaan adalah proses penghilangan material yang presisi. Kehalusan dari hasil penggerindaan juga menjadi faktor utama baik buruknya hasil penggerindaan tersebut. Singh dan Singh (2014) menyimpulkan bahwa 
parameter yang mempengaruhi kehalusan suatu produk yaitu kecepatan putar batu gerinda, kecepatan gerak benda kerja, dan tekanan alir dari cooling sistem. Sedangkan untuk mendapatkan kehalusan maksimal digunakan kecepatan putar batu gerinda 2800 RPM, dengan tekanan alir dari cooling system sebesar $25 \mathrm{~kg} / \mathrm{cm} 2$, dan kecepatan benda kerja yaitu $1,5 \mathrm{~m} / \mathrm{menit}$.

Berdasarkan faktor-faktor tersebut, dilakukan penelitian mengenai kekasaran permukaan dan ketelitian yang dicapai sebuah mesin surface grinding. Percobaan menggunakan mesin Okamoto Grind-X ACC84ST dan material DIN CK-45 yang dikeraskan. Material ini dipilih karena banyak digunakan pada bidang otomotif dan manufaktur sebagai poros, crankshaft, bushing, dan suku cadang untuk pembuatan mesin.

\section{METODE PENELITIAN}

Penelitian ini dilakukan dengan dengan urutan proses sebagai berikut: Persiapan alat dan bahan, proses penggerindaan, pengambilan dan analisis data, dan membuat kesimpulan.

Peralatan yang digunakan dalam penelitian ini adalah mesin surface grinding Okamoto Grind-X ACC84ST(Gambar 1), material uji DIN CK45 yang sudah dikeraskan dan di premachine menjadi $100 \mathrm{~mm}$ x $40 \mathrm{~mm}$ x $15 \mathrm{~mm}$, Surface Roughness Tester (Gambar 2), dan outside micrometer dengan ketelitian 0,001.

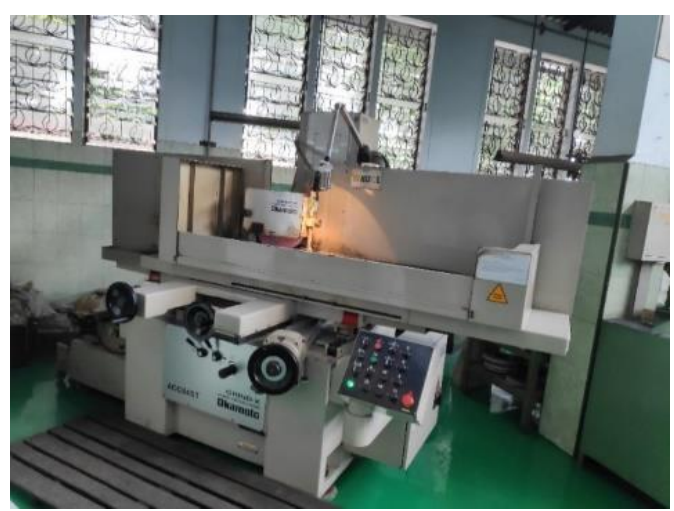

GAMBAR 1. Mesin gerinda Okamoto Grind$\mathrm{X}$ ACC84ST

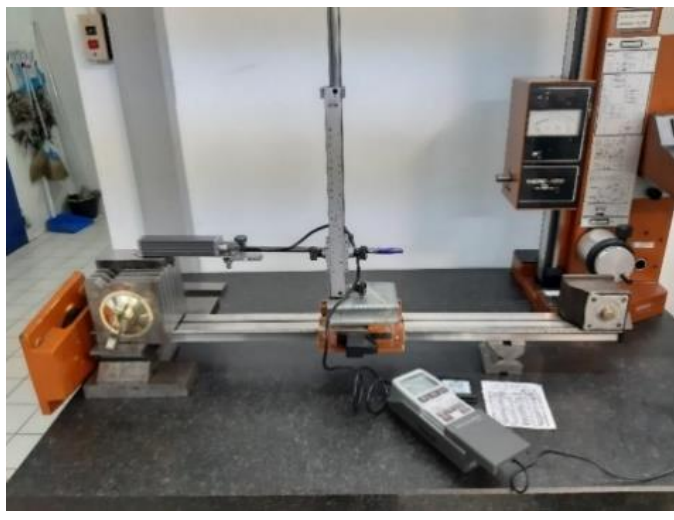

GAMBAR 2. Surface Roughness Tester

Penggerindaan dilakukan dengan mengatur parameter untuk mendapatkan hasil pengujian sesuai faktor-faktor yang mempengaruhi kualitas penggerindaan. Variasi parameter menggunakan orthogonal array Taguchi dengan 3 faktor dan 3 level. Percobaan ini menggunakan variabel feeding, depth of cut, dan siklus (banyaknya pengulangan). Percobaan dilakukan dengan pengambilan data sebanyak dua kali untuk menambah keakuratan data. Berikut adalah tabel Orthogonal Array yang sesuai dengan parameter dan level yang dipakai dalam penelitian.

TABEL 1. Orthogonal Array L9

\begin{tabular}{cccc}
\hline Percobaan & $\begin{array}{c}\text { Feeding } \\
(\mathbf{m m} / \text { menit })\end{array}$ & $\begin{array}{c}\text { Depth } \\
\text { of Cut } \\
(\mathbf{m m})\end{array}$ & $\begin{array}{c}\text { Siklus } \\
\text { (pengulangan) }\end{array}$ \\
\hline 1 & 12,5 & 0,01 & 2 \\
\hline 2 & 12,5 & 0,02 & 4 \\
\hline 3 & 12,5 & 0,03 & 6 \\
\hline 4 & 18,75 & 0,01 & 4 \\
\hline 5 & 18,75 & 0,02 & 6 \\
\hline 6 & 18,75 & 0,03 & 2 \\
\hline 7 & 25 & 0,01 & 6 \\
\hline 8 & 25 & 0,02 & 2 \\
\hline 9 & 25 & 0,03 & 4 \\
\hline
\end{tabular}

Pengukuran Kekasaran ditunjukkan pada Gambar 3: Pengukuran kekasaran dilakukan di Unit Kerja Measuring Tool ATMI Surakarta. Pengukuran dilakukan dengan menggunakan Surface Roughness Tester.

Pengukuran Kepresisian ditunjukkan pada Gambar 4: Pengukuran Kepresisian dilakukan di unit Quality Control PT. ATMI IGI Center menggunakan outside micrometer dengan graduasi $0,001 \mathrm{~mm}$. 


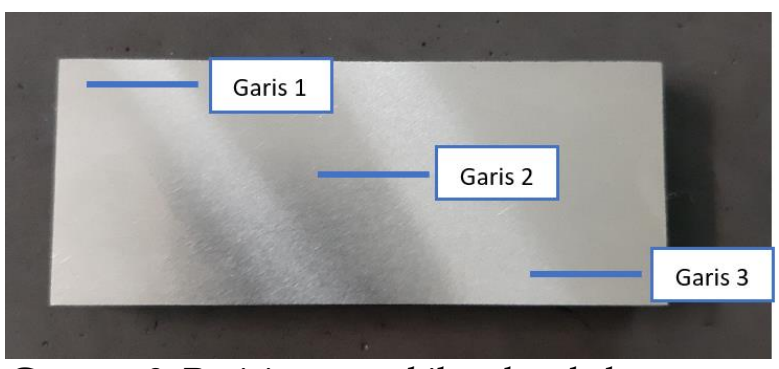

GAMBAR 3. Posisi pengambilan data kekasaran permukaan

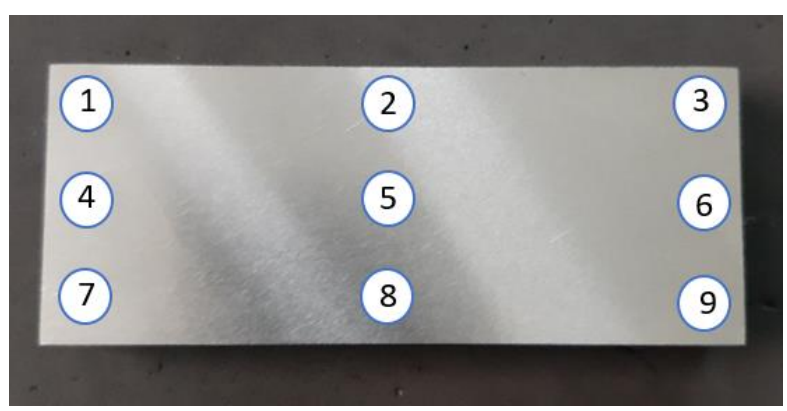

GAMBAR 4. Posisi pengambilan data ukuran (kepresisian)

\section{HASIL DAN PEMBAHASAN}

Data yang diolah adalah data kekasaran permukaan dan kepresisian (accuracy). Kekasaran permukaan diukur dengan menggunakan alat bernama Surface roughness tester sedangkan kepresisian diukur menggunakan micrometer.

Kekasaran permukaan diu.kur menggunakan surface rougness tester di bagian yang sudah ditandai seperti diilustrasikan di Gambar 3, dilakukan 2 kali pada 2 benda uji yang berbeda.

TABEL 2. Pengambilan pertama data kekasaran permukaan

\begin{tabular}{ccccc}
\hline No & $\begin{array}{c}R a \\
\text { Garis } \\
1(\mu \mathrm{m})\end{array}$ & $\begin{array}{c}R a \\
\text { Garis 2 } \\
(\mu \mathrm{m})\end{array}$ & $\begin{array}{c}R a \\
\text { Garis 3 } \\
(\mu \mathrm{m})\end{array}$ & $\begin{array}{c}R a \text { Pengambilan } \\
\text { Data 1 } \\
(\mu \mathrm{m})\end{array}$ \\
\hline 1 & 0,170 & 0,150 & 0,150 & 0,157 \\
\hline 2 & 0,100 & 0,120 & 0,100 & 0,107 \\
\hline 3 & 0,170 & 0,180 & 0,190 & 0,180 \\
\hline 4 & 0,070 & 0,080 & 0,070 & 0,073 \\
\hline 5 & 0,080 & 0,060 & 0,090 & 0,077 \\
\hline 6 & 0,150 & 0,160 & 0,160 & 0,157 \\
\hline 7 & 0,160 & 0,160 & 0,180 & 0,167 \\
\hline 8 & 0,130 & 0,150 & 0,150 & 0,143 \\
\hline 9 & 0,130 & 0,130 & 0,140 & 0,133 \\
\hline
\end{tabular}

Tabel 2 menampilkan hasil pengukuran pertama terhadap kekasaran permukaan material uji dengan variasi ke-1 sampai ke-9. Dari pengambilan data yang pertama terlihat bahwa kekasaran permukaan yang paling kecil terdapat di variasi ke-4 yaitu sebesar 0,073 $\mu \mathrm{m}$ sedangkan kekasaran paling besar terdapat di variasi parameter ke-3 yaitu sebesar $0,180 \mu \mathrm{m}$.

TABEL 3. Pengambilan kedua data kekasaran permukaan

\begin{tabular}{ccccc}
\hline No & $\begin{array}{c}R a \\
\text { Garis } \\
1(\mu \mathrm{m})\end{array}$ & $\begin{array}{c}R a \\
\text { Garis 2 } \\
(\mu \mathrm{m})\end{array}$ & $\begin{array}{c}R a \\
\text { Garis 3 } \\
(\mu \mathrm{m})\end{array}$ & $\begin{array}{c}R a \text { Pengambilan } \\
\text { Data 2 } \\
(\mu \mathrm{m})\end{array}$ \\
\hline 1 & 0,150 & 0,150 & 0,100 & 0,133 \\
\hline 2 & 0,100 & 0,100 & 0,100 & 0,100 \\
\hline 3 & 0,190 & 0,150 & 0,170 & 0,170 \\
\hline 4 & 0,070 & 0,080 & 0,080 & 0,077 \\
\hline 5 & 0,100 & 0,090 & 0,120 & 0,103 \\
\hline 6 & 0,180 & 0,160 & 0,170 & 0,170 \\
\hline 7 & 0,150 & 0,160 & 0,170 & 0,160 \\
\hline 8 & 0,140 & 0,110 & 0,120 & 0,123 \\
\hline 9 & 0,090 & 0,080 & 0,070 & 0,080 \\
\hline
\end{tabular}

Tabel 3 menampilkan hasil pengukuran kedua kekasaran permukaan material uji dengan variasi ke-1 sampai ke-9. Dari pengambilan data yang kedua terlihat bahwa kekasaran permukaan yang paling kecil terdapat di variasi ke-4 yaitu sebesar 0,077 $\mu \mathrm{m}$ sedangkan kekasaran paling besar terdapat di variasi parameter ke-3 dan ke-6 yaitu sebesar 0,170 $\mu m$.

TABEL 4. Rata-rata $R a$

\begin{tabular}{c|c|c|c}
\hline No & $\begin{array}{c}R a \\
\text { Pengambilan } \\
\text { Data Pertama } \\
(\mu \mathrm{m})\end{array}$ & $\begin{array}{c}R a \\
\text { Pengambilan } \\
\text { Data Kedua } \\
(\mu \mathrm{m})\end{array}$ & $\begin{array}{c}R a \\
\text { Pengujian } \\
(\mu \mathrm{m})\end{array}$ \\
\hline 1 & 0,157 & 0,133 & 0,145 \\
\hline 2 & 0,107 & 0,100 & 0,103 \\
\hline 3 & 0,180 & 0,170 & 0,175 \\
\hline 4 & 0,073 & 0,077 & 0,075 \\
\hline 5 & 0,077 & 0,103 & 0,090 \\
\hline 6 & 0,157 & 0,170 & 0,163 \\
\hline 7 & 0,167 & 0,160 & 0,163 \\
\hline 8 & 0,143 & 0,123 & 0,133 \\
\hline 9 & 0,133 & 0,080 & 0,107 \\
\hline
\end{tabular}

Setelah mengambil data $R a$, kemudian dilakukan penghitungan terhadap rata - rata $R a$ dari kedua pengambilan data tersebut. Tabel 4 menunjukkan kekasaran permukaan paling kecil tetap di percobaan variasi ke-4 dengan rata-rata $\mathrm{Ra}$ sebesar $0,075 \mu \mathrm{m}$ dan kekasaran 
permukaan paling besar di percobaan variasi parameter ke-3 yaitu sebesar 0,175 $\mu \mathrm{m}$. Tabel 5 adalah tabel yang digunakan untuk menemukan variabel yang paling berpengaruh terhadap kekasaran permukaan.

TABEL 5. Perhitungan variabel yang paling berpengaruh terhadap kekasaran permukaan

\begin{tabular}{cccc}
\hline & $\begin{array}{c}\boldsymbol{R a} \\
\text { terhadap } \\
\text { Depth of } \\
\boldsymbol{C u t} \\
(\boldsymbol{\mu m})\end{array}$ & $\begin{array}{c}\boldsymbol{R a} \\
\text { terhadap } \\
\text { Feeding } \\
(\boldsymbol{\mu m})\end{array}$ & $\begin{array}{c}\boldsymbol{R a} \text { terhadap } \\
\text { Siklus } \\
(\boldsymbol{\mu m})\end{array}$ \\
\hline $\begin{array}{c}\text { Level } \\
\mathbf{1}\end{array}$ & 0,1277778 & 0,141111 & 0,1472222 \\
\hline $\begin{array}{c}\text { Level } \\
\mathbf{2}\end{array}$ & 0,1088889 & 0,109444 & 0,095 \\
\hline $\begin{array}{c}\text { Level } \\
\mathbf{3}\end{array}$ & 0,1483333 & 0,134444 & 0,1427778 \\
\hline & & & \\
\hline MAX & 0,1483333 & 0,141111 & 0,1472222 \\
\hline MIN & 0,1088889 & 0,109444 & 0,095 \\
\hline $\begin{array}{c}\text { S/N } \\
\text { ratio }\end{array}$ & 0,0394444 & 0,031667 & 0,0522222 \\
\hline
\end{tabular}

Dalam Tabel 5, selisih yang terbesar mewakili variabel yang paling berpengaruh terhadap kekasaran permukaan. Variabel yang paling berpengaruh terhadap kekasaran permukaan secara berturut - turut adalah siklus, depth of cut, dan feeding. Factor paling berpengaruh adalah Siklus dengan harga $\mathrm{S} / \mathrm{N}$ ratio $(0,052)$, kemudian faktor yang kurang berpengaruh adalah depth of cut $(0,031)$, dan selanjutnya faktor paling kecil pengaruhnya adalah feeding $(0,039)$.

Kepresisian diukur dengan membandingkan antara ukuran awal dengan ukuran setelah proses penggerindaan. Hasil rata-rata didapat dari pengurangan material pada benda uji dan target diambil dari variabel depth of cut. Penyimpangan adalah hasil dari target dikurangi dengan hasil rata-rata. Kepresisian adalah penyimpangan terkecil antara depth of cut yang diatur (target) dengan pengurangan yang terjadi pada benda uji (hasil).

Hasil percobaan pertama mengenai kepresisian ditunjukkan pada Tabel 6, sedangkan percobaan kedua ditunjukkan pada Tabel 7 . Tabel 6 menunjukkan penyimpangan terkecil ada di variasi parameter ke-1, ke-5, dan ke-7 yaitu sebesar $0,001 \mathrm{~mm}$. Sedangkan penyimpangan terbesar ada di variasi parameter ke-2 yaitu sebesar $0,009 \mathrm{~mm}$.
TABel 6. Pengambilan pertama data kepresisian

\begin{tabular}{cccc}
\hline \multicolumn{4}{c}{ Penyimpangan Pengambilan Data Pertama } \\
\hline No & $\begin{array}{c}\text { Rata }- \text { Rata } \\
\text { pengurangan } \\
\text { material (mm) }\end{array}$ & $\begin{array}{c}\text { Target } \\
\text { ukuran } \\
(\mathrm{mm})\end{array}$ & $\begin{array}{c}\text { Penyimpangan } \\
(\mathrm{mm})\end{array}$ \\
\hline 1 & 0,011 & 0,01 & 0,001 \\
\hline 2 & 0,023 & 0,02 & 0,003 \\
\hline 3 & 0,035 & 0,03 & 0,005 \\
\hline 4 & 0,015 & 0,01 & 0,005 \\
\hline 5 & 0,019 & 0,02 & 0,001 \\
\hline 6 & 0,032 & 0,03 & 0,002 \\
\hline 7 & 0,009 & 0,01 & 0,001 \\
\hline 8 & 0,022 & 0,02 & 0,002 \\
\hline 9 & 0,023 & 0,03 & 0,007 \\
\hline
\end{tabular}

TABEL 7. Pengambilan kedua data kepresisian

\begin{tabular}{cccc}
\hline \multicolumn{4}{c}{ Penyimpangan Pengambilan Data Pertama } \\
\hline No & $\begin{array}{c}\text { Rata - Rata } \\
\text { pengurangan } \\
\text { material (mm) }\end{array}$ & $\begin{array}{c}\text { Target } \\
\text { ukuran } \\
(\mathrm{mm})\end{array}$ & $\begin{array}{c}\text { Penyimpangan } \\
(\mathrm{mm})\end{array}$ \\
\hline 1 & 0,010 & 0,01 & 0,000 \\
\hline 2 & 0,021 & 0,02 & 0,001 \\
\hline 3 & 0,033 & 0,03 & 0,003 \\
\hline 4 & 0,010 & 0,01 & 0,000 \\
\hline 5 & 0,019 & 0,02 & 0,001 \\
\hline 6 & 0,027 & 0,03 & 0,003 \\
\hline 7 & 0,010 & 0,01 & 0,000 \\
\hline 8 & 0,024 & 0,02 & 0,004 \\
\hline 9 & 0,022 & 0,03 & 0,008 \\
\hline
\end{tabular}

Data penyimpangan, kemudian dilakukan penghitungan rata - rata penyimpangan dari kedua pengambilan data tersebut.

TABel 8. Pengambilan kedua data kepresisian

\begin{tabular}{c|c|c|c}
\hline No & $\begin{array}{c}\text { Penyimpangan } \\
1(\mathrm{~mm})\end{array}$ & $\begin{array}{c}\text { Penyimpangan } \\
2(\mathrm{~mm})\end{array}$ & $\begin{array}{c}\text { Rata }- \\
\text { Rata } \\
(\mathrm{mm})\end{array}$ \\
\hline 1 & 0,001 & 0,000 & $\mathbf{0 , 0 0 0 5}$ \\
\hline 2 & 0,003 & 0,001 & $\mathbf{0 , 0 0 2}$ \\
\hline 3 & 0,005 & 0,003 & $\mathbf{0 , 0 0 4}$ \\
\hline 4 & 0,005 & 0,000 & $\mathbf{0 , 0 0 2 5}$ \\
\hline 5 & 0,001 & 0,001 & $\mathbf{0 , 0 0 1}$ \\
\hline 6 & 0,002 & 0,003 & $\mathbf{0 , 0 0 2 5}$ \\
\hline 7 & 0,001 & 0,000 & $\mathbf{0 , 0 0 0 5}$ \\
\hline 8 & 0,002 & 0,004 & $\mathbf{0 , 0 0 3 5}$ \\
\hline 9 & 0,007 & 0,008 & $\mathbf{0 , 0 0 7 5}$ \\
\hline
\end{tabular}


Tabel 8 menunjukkan bahwa rata-rata penyimpangan terkecil ada di variasi parameter ke-1 dan ke-7 yaitu sebesar 0,0005 mm. sedangkan pada variasi parameter ke-9 yaitu sebesar 0,0075 $\mathrm{mm}$. Langkah selanjutnya adalah menemukan variabel apa yang paling berpengaruh pada hasil kepresisian penggerindaan.

TABEL 9. Pengambilan kedua data kepresisian

\begin{tabular}{cccc}
\hline & $\begin{array}{c}\text { Deviasi } \\
\text { terhadap } \\
\text { Depth of } \\
\text { Cut } \\
(\mathbf{m m})\end{array}$ & $\begin{array}{c}\text { Deviasi } \\
\text { terhadap } \\
\text { Feeding } \\
(\mathbf{m m})\end{array}$ & $\begin{array}{c}\text { Deviasi } \\
\text { terhadap } \\
\text { Siklus } \\
(\mathbf{m m})\end{array}$ \\
\hline Level 1 & 0,0011 & 0,0021 & 0,0021 \\
\hline Level 2 & 0,0020 & 0,0020 & 0,0039 \\
\hline Level 3 & 0,0046 & 0,0037 & 0,0017 \\
\hline MAX & 0,0046 & 0,0037 & 0,0039 \\
\hline MIN & 0,0011 & 0,0020 & 0,0017 \\
\hline Selisih & 0,0035 & 0,0017 & 0,0022 \\
\hline
\end{tabular}

Tabel 9 adalah perhitungan yang digunakan untuk menemukan variabel yang paling berpengaruh terhadap kekasaran permukaan. Dalam tabel tersebut, selisih yang terbesar mewakili variabel yang paling berpengaruh terhadap kekasaran permukaan. Dalam hal ini, maka variabel yang paling berpengaruh terhadap kekasaran permukaan secara berturutturut adalah depth of cut, siklus, dan feeding.

\section{KESIMPULAN}

Berdasarkan hasil dari pengujian yang telah dilakukan, didapatkan kesimpulan variabel yang paling berpengaruh terhadap kekasaran permukaan hasil proses surface grinding menggunakan material DIN CK-45 adalah siklus per penyayatan. Variabel yang paling berpengaruh terhadap kepresisian hasil surface grinding menggunakan material DIN CK-45 adalah depth of cut. Sedangkan kekasaran yang bisa dicapai menggunakan mesin Okamoto Grind-X ACC84ST adalah berkisar antara $0,075 \mu \mathrm{m}$ (N3) hingga $0,175 \mu \mathrm{m} \quad(\mathrm{N} 4)$. Penyimpangan ukuran yang terjadi dalam penelitian ini berkisar antara $0,0075 \mathrm{~mm}$ hingga $0,005 \mathrm{~mm}$.

\section{UCAPAN TERIMA KASIH}

Penulis dapat menuliskan ucapan terima kasih kepada pihak-pihak yang telah membantu dalam penelitian yang dipublikasikan dalam jurnal ini.

\section{DAFTAR PUSTAKA}

Banga, T. R., \& Sharma, S. C. 2009. Mechanical Engineering Handbook, Fourth Edition, Khanna Publishers.

Instruction Manual ACC-ST Series ACC84ST. (2011). Dokumen Teknis, Okamoto Machine Tool Works, LTD, Jepang

Kumar, S., \& Bhatia, O. S. 2015. Review of analysis \& optimization of cylindrical grinding process parameters on material removal rate of En15AM steel. IOSR Journal of Mechanical and Civil Engineering, 12(4), 35-43.

Kumar, S., \& Dhanabalan, Dr. S. 2018. A Review of Cylindrical Grinding Process parameters by using various Optimization techniques and their effects on the surface Integrity, Wear Rate and MRR. International Journal of Advance Engineering and Research Development, 5:719.

Singh, B., \& Singh, B. 2014. Effect of process parameters on micro hardness of mild steel processed by surface grinding process. IOSR journal of mechanical and civil engineering, 10(6), 61-65. 